\title{
Planning Skills as a Correlate of Selfregulated Learning Skills and Learning Outcomes Among Adolescents in Secondary Schools in The South West Region of Cameroon
}

\author{
Veronica Ika Kum \\ Ph.D. Research Fellow, Department of Educational Psychology, \\ Faculty of Education, University of Buea, Cameroon, Central Africa
}

\section{ABSTRACT}

This study investigated "planning skills as a correlate of self-regulated learning skills and learning outcomes of adolescents in secondary schools in the Southwest region of Cameroon. By failing to employ selfregulated learning skills and Meta cognitive strategies in learning such as planning skills, learners have become more passive than active participants in a community of learners who should be engaged in meaning making in the learning process. In this light, this study examined whether planning skills as a correlate of self-regulated learning skills influences learning outcomes of adolescents. The research designs adopted for this study were the descriptive survey design with the aid of a structured questionnaire as the main research instrument and a quasi-experimental research design. To answer the research question, copies of questionnaire were administered to a sample of 451 participants and data from the 451 participants were effectively analysed, from which conclusions were drawn. Data were analysed following a triangulation approach in methodology, analytical process and statistical packages. Based on the analyses of data, it was realised that; there exist a significant relationship between planning as a self-regulated learning skill and learning outcomes of adolescents in secondary schools $(\mathrm{r}=0.120, \mathrm{n}=451, \mathrm{p}<0.05)$. Inferring from above, it can be seen that, planning as a correlate of self-regulated learning skills influences the learning outcomes of adolescents in secondary schools. At the end of the study, it was therefore recommended that teachers and educators should strive as much as possible to help learners to develop their selfregulated learning skills such as planning so as to improve upon adolescents' learning outcomes.
Keyword: Planning Skills, Self-Regulated Learning Skills, Learning Outcome, Adolescents

\section{INTRODUCTION}

The educational paradigm of the 21st Century advocates the learner as the principal agent in the teaching/learning process and underscores the importance of context and pedagogical tools. SelfRegulated Learning (SRL) as a concept in teaching and learning became intense in the 1980s with focus on the learners taking ownership and control of their own learning. There was indeed a paradigm shift from teacher centred classrooms to learner centred classrooms with emphasis on how the learner processes information. In an era of ever changing science and technology, it is important to teach students how to learn. Presently, psychology of education highlights on intrinsic motivation and autonomous learning in order to achieve this kind of outcome (Pint rich, 2000; Cheng, 2000).

By inference, SRL espouse the learners to be managers of their own learning by appropriately emphasizing goal directed behaviour, planning, monitoring, and evaluation. It focuses on specific learning skills adolescents use and the extent to which these skills can regulate learning outcomes of adolescents in secondary schools. Many recent studies have stressed the importance of students' selfregulated learning skills (SRLS) for successful learning. As such a significant number of studies have been done in education to demonstrate that selfregulated learning can influence learners' academic performance and aid learning motivation (Zimmerman \& Martineze-Pons, 1986, 1998; Pint rich, 2000, 2004; Lin \& Chen 1995). Literature indicates that there is an interaction between self- 
regulated learning and performance of learners. However, there exist just few studies that have attended to the self-regulated learning and met a cognitive strategies of secondary schools adolescents in Cameroon classrooms. There is need therefore to explore and understand the benefits of using selfregulated learning strategies in this specific area of the South West Region of Cameroon. Although secondary schools teachers and students may be aware of the influence of self-regulated leaning skills for the present day classroom and students in particular, they often find it difficult to implement SRL in teaching/learning activities.

This study therefore becomes an important resource for future research in this domain, providing data and filling the gaps left in the Cameroonian context which has not been addressed by existing literature. It also ushers in an original agenda for educational practitioners, school counsellors, adolescent students and other stakeholders in the preparation of the next generation of Cameroon. It finally provides new directions for a theoretical framework that explains planning skills as a correlate of self-regulated learning skills in relation to learning outcomes among adolescent students in secondary schools based on Cameroon and African realities.

\section{Method}

Both quantitative and qualitative research paradigms were taken into consideration to conduct this study. To begin with, in order to collect quantitative data, the descriptive survey design with the aid of a questionnaire as well as a quasi-experimental design was used in conducting this study. In addition, to collect qualitative data, the ethnographic and phenomenological approaches with the aid of an Interview Guide were used in conducting this study. To answer the research question on how planning skills influence learning outcomes of adolescent students, copies of questionnaire were administered to a sample of 451 participants and data from the 451 participants were effectively analysed, from which conclusions were drawn.

Data were analysed using both descriptive and inferential statistics. To this effect descriptive statistics such as percentages, mean and standard deviations were used. Data were analysed using SPSS version 20.0 and Microsoft Excel 2010. The effect of planning skills as a correlate of self-regulated learning skills on learning outcomes of adolescents in secondary schools was quantified to obtain the effect score for (planning skills). This was computed for individual cases and for the entire study population to obtain the overall effect.

Data were screened for reliability using the Cronbach's Alpha test and it was evident that the internal consistency was not violated for all the conceptual components including the integrated value mapping (IVM) as Alpha values were all greater than 0.5 . The data was then validated for analysis.

In examining the relationship between planning skills as a correlate of self-regulated learning skills and learning outcomes, a correlation coefficient and level of significance were used to evaluate the relationship between learning outcome and each of the variables under observation. A positive value for $\mathrm{R}$ indicated a positive correlation and the $\mathrm{p}$-value indicated the level of significance of the relationship.

For the quasi experiment design, a comparison was made for the mean score between the control group and the experimental group for both the pre-test and the post-test. The scores of the post-test and the pretest were also categorized into two groups; those who performed above average and those who performed below average and compared using chi-square test of equality of proportion.

As for qualitative data, notably perceptions of students on how planning skills with regards to learning and understanding could be improved; content thematic analysis was used to organize ideas or viewpoints under umbrella terms with the support of Atlas Ti 5.2.

All statistics were discussed at the 95\%, CL (Alpha $=0.05)$ and presented using statistical tables and charts. The findings are presented following the research questions of the study.

\section{Measures}

Items were measured with the aid of a 5-point Likert scale questionnaire where by respondents were required to state how they feel about each item, that is by stating whether they strongly agree (SA), agree (A), disagree (D), strongly disagree (SD) and undecided (U), pertaining to the variables of the study. To facilitate analysis, responses were further collapsed into three categories (agreed, undecided and disagreed) as clearly shown in table 1 below. 
International Journal of Trend in Scientific Research and Development (IJTSRD) ISSN: 2456-6470

Table 1: Distribution of indicators of planning skills

\begin{tabular}{|c|c|c|c|c|}
\hline Items & A & $\mathrm{U}$ & D & $\mathbf{N}$ \\
\hline I set goals of learning that I want to achieve & $417(92.5 \%)$ & $23(5.1 \%)$ & $11(2.4 \%)$ & 451 \\
\hline $\begin{array}{l}\text { I draw up a reading timetable for myself to plan for } \\
\text { reading so as to master the learning goals }\end{array}$ & $392(86.9 \%)$ & $27(6.0 \%)$ & $32(7.1 \%)$ & 451 \\
\hline I always jot down difficult concepts when reading & $381(84.5 \%)$ & $43(9.5 \%)$ & $27(6.0 \%)$ & 451 \\
\hline $\begin{array}{l}\text { I always make a list of difficult questions when } \\
\text { studying }\end{array}$ & $321(71.2 \%)$ & $79(17.5 \%)$ & $51(11.3 \%)$ & 451 \\
\hline $\begin{array}{l}\text { Usually I think of which friends can give me help } \\
\text { with difficult problems }\end{array}$ & $377(83.6 \%)$ & $40(8.9 \%)$ & $34(7.5 \%)$ & 451 \\
\hline $\begin{array}{l}\text { I take note of important ideas and concepts when } \\
\text { studying }\end{array}$ & $401(88.9 \%)$ & $33(7.3 \%)$ & $17(3.8 \%)$ & 451 \\
\hline I always make a list of questions to ask my teachers & $277(61.4 \%)$ & $91(20.2 \%)$ & $83(18.4 \%)$ & 451 \\
\hline $\begin{array}{c}\text { When I summarize I put down ideas in my own } \\
\text { words }\end{array}$ & $377(83.6 \%)$ & $46(10.2 \%)$ & $28(6.2 \%)$ & 451 \\
\hline $\begin{array}{l}\text { I do not only read the teacher's notes but consult } \mathrm{C} \\
\text { other materials as well }\end{array}$ & $352(78.0 \%)$ & $54(12.0 \%)$ & $45(10.0 \%)$ & 451 \\
\hline I usually read the chapter before the lesson is given & $228(50.6 \%)$ & $104(23.1 \%)$ & $119(26.4 \%)$ & 451 \\
\hline $\begin{array}{l}\text { I usually chose a quiet and comfortable place to } \\
\text { study }\end{array}$ & $365(80.9 \%)$ & $52(11.5 \%)$ & $34(7.5 \%)$ & 451 \\
\hline I know when it is appropriate for me to play & $322(71.4 \%)$ & $79(17.5 \%)$ & $50(11.1 \%)$ & 451 \\
\hline $\begin{array}{l}\text { I plan for a weekly schedule for studies and follow it } \\
\text { up strictly. }\end{array}$ & $271(60.1 \%)$ & $90(20.0 \%)$ & $90(20.0 \%)$ & 451 \\
\hline I come up with objectives when studying & $290(64.3 \%)$ & $78(17.3 \%)$ & $83(18.4 \%)$ & 451 \\
\hline $\begin{array}{l}\text { I just read and understand the information the } \\
\text { teacher gives me in class without analysing }\end{array}$ & $157(34.8 \%)$ & $72(16.0 \%)$ & $222(49.2 \%)$ & 451 \\
\hline I have all the text books in all my subjects & $194(43.0 \%)$ & $73(16.2 \%)$ & $184(40.8 \%)$ & 451 \\
\hline $\begin{array}{l}\text { I always decide on which learning activity to pay } \\
\text { attention to in order to } 1\end{array}$ & $295(65.4 \%)$ & 70 & $86(19.1 \%)$ & 451 \\
\hline $\begin{array}{l}\text { I get easily carried away by other things from my } \\
\text { plan. }\end{array}$ & $246(54.5 \%)$ & $70(15.5 \%)$ & $135(29.9 \%)$ & 451 \\
\hline I have difficulty making up my mind about things & $240(53.2 \%)$ & $68(15.1 \%)$ & $143(31.7 \%)$ & 451 \\
\hline I have trouble making plans to help reach my goals & $245(54.3 \%)$ & $48(10.6 \%)$ & $158(35.0 \%)$ & 451 \\
\hline Multiple Response Set (MRS) & $6148(68.2 \%)$ & $1240(13.7 \%)$ & $1632(18.1 \%)$ & 9020 \\
\hline
\end{tabular}

From the above table, the responses indicated that most students were conscious on the efforts they put in planning while learning in school. Very few responses $(13.7 \%)$ were 'undecided', indicating that a lesser proportion of students were unconscious on whether they plan or not when learning. However, majority of the responses were in agreement with statements suggesting different aspects of planning carried out by high school students (MRS $=68.2 \%$, $\mathrm{n}=9020$ ). This is evidence that proper planning is common among high school students and contributes largely to learning outcome. Setting goals (92.5\%), taking notes of important ideas and concepts when studying $(88.9 \%)$ and drawing up a reading timetable to follow (86.9\%), are amongst the top shared ideas related to planning among students. In general, students agreed to majority of the statements relating to planning. The least shared ideas were "I just read and understand the information the teacher gives me in class without analysing" (34.8\%), and "I have all the text books in all my subjects" (43.0\%). This suggests that some aspects of "note taking" and organization are lagging in high school students. 
International Journal of Trend in Scientific Research and Development (IJTSRD) ISSN: 2456-6470

Results Table2: Correlation test depicting the relationship between planning skills in students and aspects of learning outcome

\begin{tabular}{|c|c|c|}
\hline \multirow{2}{*}{ Learning outcomes } & \multicolumn{2}{|c|}{ Planning } \\
\cline { 2 - 3 } & Correlation coefficient & p-value \\
\hline Contributing to classroom discussions & 0.042 & 0.370 \\
\hline Confidently communicating with teachers and peers & 0.097 & $0.038^{*}$ \\
\hline Exploring and trying new things learnt & 0.064 & 0.174 \\
\hline Transfer and adapt knowledge to real life situations & 0.065 & 0.165 \\
\hline Ability to plan, self-monitor and self-evaluate. & 0.036 & 0.449 \\
\hline Overall statistics & $\mathbf{0 . 1 2 0}$ & $\mathbf{0 . 0 1 0}$ \\
\hline
\end{tabular}

In examining the relationship between planning skills of adolescent students and its effects on their learning outcomes, a correlation test was used. The correlation test in the above table indicates that all the different components of planning skills have a positive relationship with learning outcomes. This simply means that the more students gain skills in planning, the more likely they can perform better in classroom learning.

Though the relationship between planning and learning outcome is weak, the correlation coefficient is positive for all the different aspects of learning and overall it is statistically significant $(r=0.120$; $\mathrm{p}=0.010$ ) at the $95 \%$ confident level. This significant value clearly shows that there is a significant relationship between planning and learning outcomes of students. To conclude, it was realised that, planning skills as a correlate of self-regulating learning skills, significantly influences learning outcomes among adolescent students in secondary schools.

\section{Discussion}

The above findings indicates that a significant number of students (MRS $=68.2 \%, \quad n=9020)$ were in agreement, suggesting different aspects of planning carried out by high school students. It equally shows that proper planning is evident among high school students and contributes significantly to learning outcomes. When specific learning skills were examined, they further confirmed the results as setting goals $(92.5 \%)$, taking notes of silent concepts and ideas when studying $(88.9 \%)$, drawing up a reading timetable to follow (86.9\%), summarization of main ideas when studying (83.6\%) were among the high skills exhibited relating to planning.

In examining the relationship between planning skills of students and outcome of learning, a correlation test was used. Based on the correlation test, it was realised that all the different components of learning outcome have a positive relationship with planning. This simply means that the more students gain skills in planning, the more likely they can perform better in classroom learning.

Though the relationship between planning and learning outcome is weak, the correlation coefficient is positive for all the different aspects of learning and overall it is statistically significant $(r=0.120$; $\mathrm{p}=0.010$ ) at the $95 \%$ confident level. This significant value clearly shows that there is a significant relationship between planning and learning outcomes of students. This is finding is consistent with the works of (Elliot, 2010; Kistner, Rakczy, \& Otto 2010; Kitsantas \& Zimmerman 2005) in which 132 students were asked to identify factors that they considered important in learning and most of them cited planning.

Findings from the thematic analysis in relation to the perception on how learning and understanding could be improved in different study areas shows that $12 \%$ of students were of the opinion that management of study time as a component of planning is important and $8 \%$ indicated that they need to be taught learning strategies while another $8 \%$ indicated that students on their part need to internalize positive learning attitudes. These were students' perceptions relating to this aspect:

$>$ More time should be given for individual study

$>$ Personal study time table will help

$>$ Give me enough time to study on my own

$>$ Proper planning of my learning activities

$>$ Teachers should change teaching methods and strategies

$>$ We should read textbooks and make our own notes.

Because self-regulated learning takes place over time, before (planning) which precedes the learning tasks; during (monitoring) which takes place during 
learning; and after (evaluating) which occurs immediately after learning to access, it does not need specific levels of ability of intelligence (Schraw, 1994), instead it considers learning about the practices and the benefits. Students in classrooms who encourage self-regulated learning exhibit higher levels of concentration and behaviour directed towards the achievement of educational and personal goals. They truly believe they can learn and improve outcomes, they devote more time to their tasks, process information deeply, and exhibit autonomy and greater levels of effort.

Unlike students in these classrooms who are aware to develop their skills by selecting their own activities and taking initiative in acquiring both subject and strategy knowledge, their counterparts in classrooms that involve limited scope of skills, do less well, achieve lower in academic outcomes measures (Nolen \& Haladyna (1990a. 1990b; Zimmerman \& Schunk,. 2011) and classroom activities are closely dependent on the teacher. Findings for this study show the following characteristics as such:

$>$ Teachers should give us notes or teachers should give us well organized notes

$>$ Notes should be photocopied and given to students

$>$ Teachers should check student notes and explain them very well

$>$ Teachers should ask questions as they teach.

$>$ Teachers should teach us how to learn and to answer questions

$>$ Teachers should explain everything slowly and be there always

$>$ The best way to teach is to use charts, pictures and practical

This is inconsistent with help-seeking: indicating student-initiated efforts to solicit help from peers or teachers. Self-regulation can be enhanced by appropriate guidance, modelling of effective learning strategies and skills development which are developed from early childhood to adolescence during which the aim of education may be focused on self-regulation and skills. This gives a proper transition to autonomy which is an important dimension in self-regulation. However, Chiu, (1998) established that low ability students benefit slightly more from learning strategies. It is then not surprising, that many other students in the classroom are yet not willing or lack the skills to take responsibility for their own learning as shown in the information above. They feel coerced to achieve learning goals, scoring lower on academic outcomes or performance. This finding indicates that for most subject areas, it is important to instruct students in learning strategies in order to improve performance.

From the findings, high school students from the different institutions suggested many other solutions that could improve on learning and understanding in different subject areas. It also shows that $66 \%$ of students believe proper planning and effective time management can improve on their learning, though for different reasons. While some students think planning enables them to work on all subjects, others think if time is well managed, their grades will significantly improve. Planning according to some students encourage them to go beyond their limits and for another group of students, proper planning creates awareness and consciousness in students, improves their learning, helps them to be focus and devoted. In general, planning largely contributes to learning as students agreed to majority of statements relating to planning.

Consistent with this study, Andertonn (2006) investigated the relationship between academic success and use of goal planning, weekly monitoring, and evaluation forms within an online class to promote the use of self-regulated learning strategies with two sections of students $(n=28)$. And ertonn (2006) administered the MSLQ pre-intervention and post-intervention and compared results with average quiz scores of the two sections of students. The strength of the relationship between the worksheets and the participants' perceived ability to self-regulate in an online course was strong, as assessed by the partial $\eta 2=.25$. The goal analysis sheets and selfregulated worksheets accounted for $25 \%$ of the score variance on the post-test MSLQ. Based on these results, Andertonn (2006) posited that participants in the experimental group of this study appeared to increase their ability to self-regulate as measured by the increase in their scores on the final MSLQ. Although students with higher self-regulatory skills had higher average quiz scores, they were not statistically significantly higher than those participants in the comparison group who did not show increased ability to use self-regulatory skills based on their post-MSLQ scores. Findings in this area were not statistically significant to support the literature which argues that increased self-regulated learning ability leads to academic success (Zimmerman \& Martinez-Pons, 1986). 


\section{Conclusion}

The findings from this study are outstanding because they provide greater insight into understanding planning skills as a correlate of self-regulated learning skills and its influence on adolescent learners learning outcome in Southwest region, Cameroon, Africa and around the world in general. The findings also confirm the supposition that adolescents in other emerging economies, adolescents in Southwest region of Cameroon within their different schools; make use of planning skills as a correlate of self-regulated learning skills which has a positive influence on their learning outcomes. In fact, the results of this study indicate that, planning skills as a correlate of selfregulated learning skills in this study influences adolescent learners' learning outcomes. Such skills can also be instilled onto learners by teachers and educators so as to improve upon the learning outcomes of learners within classrooms and school settings.

\section{References}

1. Pint rich, P. (2000). Multiples goals, multiple pathways: the role of goal orientation in learning and achievement. Journal of 1 Educational Psychology, 92, 544-555.

2. Cheng, C S. (2000). Self-regulated learning strategies and achievement in an introduction to information system course. Information technology, learning and performance journal 20(1), Sping 2002.

3. Andertonn, B. (2006). Using online course to promote self-regulated learning strategies in preservice teachers. Journal of Interactive online learning, 5, 156-177.

4. Chiu, C. W. T. (1998). Synthesizing met a cognitive interventions: What training characteristics can improve reading performance? Paper presented at the annual meeting of the American Educational Research Association, San Deigo, CA.

5. Cohen J. (1998). Statistical power analysis for the behavioural science $\left(2^{\text {nd }}\right.$ ed.) Hillsdle, $\mathrm{NJ}$ : Erlbaum. Cox.

6. Elliot, A.J (2007). A conceptual history of the achievement goal construct, In A. Elliot \& C. S Dweck (Eds.), handbook of competence and motivation (pp.52-72). New York: Guilford Press.

7. Kitsantas, A., \& Zimmerman, B. J. (2005). The hiden dimension of personal competence: selfregulated learning and practice. In A. J. Elliot \& C. S. Dweck (Eds.), Handbook of competence and motivation (pp. 509-526). New York: Guilford Press.

8. Labhn, A. S., Zimmerman B. J., \& Hassel horn, M. (2010). Enhancing students' self-regulation and mathematics performance: the influence of feedback and self-evaluative standards met a cognition and learning, 592), 173-194.

9. Lin, J. P., \& Chen (1995). Supervising learning: theoris and practices. Taipei: Wunan Press.

10. Nolen, S. B. \& Haladyna, T. M. (1990a). Motivation and studying in high school science: Journal of Research in Science teaching, 27, 115126.

11. Nolen, S. B. \& Haladyna, T. M. (1990b). A construct validation of measures of students' study strategy beliefs and perception of teacher goals. Educational and Psychology Measurement, 191202.

12. Pint rich, P. R., \&Zusho, A. (2004).The development of academic self-regulation: The role of cognitive and motivational factors. San Diego, CA: Academic Press.

13. Ryan, A. M., Pint rich, P. R., \& Midley, C. (2001). Avoiding seeking help in the classroom: Who and why? Educational Psychology Review, 13 9-114.

14. Schraw, G., Crippen, K. J., Hartley, K. (2006). Promoting self-regulation in science education. Met a cognition as part of a broader perspective on learning. Research in Science Education, 36, 111-139.

15. Schraw, G. (2010) Measuring self-regulation in computer-based learning environment. Educational Psychology, 45, 258-266

16. Schraw, G., \& Dennison, R. S. (1994). Assessing met a cognitive awareness. Contemporary Educational Psychology, 19(4), 460-475.

17. Zimmerman, B. J (1998), Academic studying and the development of personal skills: A selfregulatory perspective, Educational Psychology, 73-86.

18. Zimmerman, B.J, \& Martinez-Pons, M. (1986).Development of a structured interview for assessing student use of self-regulated learning strategies: American Educational Research Journal, 23, 614-628.

19. Zimmerman, B. J., \& Schunk, D. H. (2011). Selfregulated learning and performance. In B. J Zimmerman and D. H. Schunk (Eds.), Handbook of self-regulation of learning and performance (pp. 1-12). New York: Rout ledge. 